\title{
METODOLOGIA DA PROBLEMATIZAÇÃO NO ENSINO DE PRIMEIROS SOCORROS PARA CRIANÇAS NA ESCOLA: RELATO DE EXPERIÊNCIA
}

\section{METHODOLOGY OF PROBLEMATIZATION IN TEACHING FIRST AID TO CHILDREN IN SCHOOL: EXPERIENCE REPORT}

\author{
Thaíne Leal da Silva ${ }^{1} *$ Juliana Silveira Colomé ${ }^{2} *$ Adriana Dall'Asta Pereira $^{3} *$ Leonardo $^{*}$ \\ Londero Orsolin ${ }^{4} *$ Keity Laís Siepmann $\operatorname{Soccol}^{5} *$ Carla Lizandra de Lima Ferreira $^{6}$
}

\begin{abstract}
RESUMO
Objetivo: Relatar o processo de ensino aprendizagem de primeiros socorros na escola por meio da utilização do Arco de Maguerez. Método: Trata-se de um relato de experiência desenvolvido por uma estudante de enfermagem sobre o processo de ensino aprendizagem de primeiros socorros na escola, que utilizou para o seu desenvolvimento como base metodológica problematizadora o Método do Arco de Charlez Maguerez. Resultados: O uso da metodologia da problematização para o ensino de primeiros socorros se mostrou importante à medida que organizou o processo de ensino aprendizagem, e promoveu a constante reflexão, o pensamento crítico, a formação e autonomia das crianças envolvidas. Conclusão: O método desencadeou uma transformação da realidade social na escola, pois contribuiu para a ampliação significativa no conhecimento das crianças. E, as etapas propostas pelo método trouxeram como implicações na prática a transformação social.

Palavras-chave: Enfermagem. Educação em Saúde. Serviços de Saúde Escolar. Primeiros Socorros. Aprendizagem Baseada em Problemas.
\end{abstract}

\begin{abstract}
Aim: Report the teaching and learning process of first aid at school using the Arco de Maguerez. Method: This is an experience report developed by a nursing student about the teaching-learning process of first aid at school, who used Charlez Maguerez' Arch Method as a problematizing methodological basis. Results: The use of the problematization methodology for teaching first aid proved to be important as it organized the teaching-learning process, and promoted constant reflection, critical thinking, training and autonomy for the children involved. Conclusion: The method triggered a transformation of the social reality at school, as it contributed to a significant increase in children's knowledge. And, the steps proposed by the method brought practical implications for social transformation.
\end{abstract}

Keywords: Nursing. Health Education. Health Services School. First Aid. Problem-Based Learning.

\footnotetext{
${ }^{1}$ Enfermeira graduada pela Universidade Franciscana (UFN). Mestranda em enfermagem pela Universidade do Minho. ORCID: https://orcid.org/0000-0002-0501-2209

${ }^{2}$ Doutora em enfermagem. Docente dos cursos de graduação em enfermagem e Mestrado em Ciências da Saúde e da Vida da Universidade Franciscana (UFN). Membro do GEPESES. ORCID: https://orcid.org/0000-0002-8059-1482

${ }^{3}$ Enfermeira. Doutora em Ciências pela UNIFESP. Docente do curso de enfermagem da Universidade Franciscana (UFN). ORCID: https://orcid.org/0000-0003-2698-2711

${ }^{4}$ Enfermeiro. Mestre em Ciências da Saúde e da Vida pela Universidade Franciscana (UFN).

ORCID: https://orcid.org/0000-0001-8757-1137

${ }^{5}$ Enfermeira. Doutora em Enfermagem. Docente do curso de graduação em enfermagem da Universidade Franciscana (UFN). ORCID: https://orcid.org/0000-0002-7071-3124

${ }^{6}$ Enfermeira. Doutora em Ciências. Coordenadora e docente do curso de graduação em enfermagem da Universidade Franciscana (UFN). ORCID: https://orcid.org/0000-0003-0759-7113
} 


\section{INTRODUÇÃO}

No Brasil, as principais causas de morte consideradas acidentais em crianças envolvem o afogamento, acidentes de trânsito, sufocação, queimadura, queda e intoxicação. Enquanto que as principais causas de internação são devido a quedas, queimaduras, acidentes de trânsito, intoxicação, sufocação e afogamento $^{(1)}$.

No que se refere à acidentes que envolvem as crianças nas escolas, ainda não se tem dados suficientes, no entanto, sabe-se que os mesmos ocorrem $^{(2)}$. Os estudos existentes até o momento, evidenciam que os educadores já presenciaram acidentes de diferentes tipos, que vão desde quedas, ferimentos, fraturas, aspiração de corpo estranho, choque elétrico, entre outros ${ }^{(3)}$. Entretanto, muitos desses acidentes são possíveis de serem evitados quando se adota medidas de prevenção ${ }^{(4)}$.

Quando os acidentes ocorrem é necessária uma aplicação rápida dos primeiros socorros às vítimas para que se possa manter a vida. O termo primeiros socorros é definido como as medidas iniciais e imediatas aplicadas à vítima, onde são realizadas ações por pessoas treinadas, na tentativa de manter os sinais vitais e a preservação da vida, e evitar o agravamento de lesões existentes, até que uma equipe especializada possa transportá-la ao hospital e oferecer um tratamento definitivo ${ }^{(5)}$.

Qualquer pessoa, seja ela leiga ou não, pode aplicar os primeiros socorros, desde que possua conhecimento básico, teórico ou prático, para intervir na situação ${ }^{(6)}$. As situações de urgência e emergência podem ocorrer em qualquer local $^{(7)}$, inclusive no ambiente escolar.

Desde o ano de 2018, o Brasil sancionou a lei número 13.722 em que torna obrigatória a capacitação em noções de primeiros socorros para professores e funcionários de instituições de ensino públicas e privadas, que englobem a educação básica e de recreação infantil ${ }^{(8)}$. Investir na capacitação sobre primeiros socorros permite um atendimento adequado e de qualidade para a vítima, até que ocorra a chegada de um serviço de emergência especializado ${ }^{(6)}$. Assim, a capacitação de professores e funcionários deixam esses profissionais aptos a prestarem os primeiros socorros ${ }^{(2)}$.

No entanto, a lei torna obrigatória a capacitação aos professores e funcionários, e não envolve o ensino aos estudantes ${ }^{(8)}$. Nesse sentido, ensinar as crianças sobre primeiros socorros também torna-se fundamental, à medida em que os acidentes podem ocorrer tanto no ambiente escolar, quanto no domicílio. 
Em alguns países essa prática de ensino e de educação em saúde às crianças já vem sendo difundida. É essencial que o acesso ao conhecimento de primeiros socorros seja disseminado para a sociedade para que as pessoas consigam cuidar da saúde e estarem menos expostas à riscos. Pessoas capacitadas e bem treinadas desde a educação básica para agir rapidamente e com desenvoltura em situações que comprometem a vida, evitam ou minimizam possíveis desfechos negativos ${ }^{(7)}$.

A educação em saúde nas escolas ganhou visibilidade a partir da Política Nacional de Atenção Básica, que instituiu o Programa Saúde na Escola (PSE). Esse Programa incentiva a formação dos estudantes por meio de ações de prevenção, promoção e atenção à saúde. E, reafirmou o compromisso dos profissionais de saúde, dentre esses, o enfermeiro de atuarem nesses cenários $^{(9)}$. Portanto, o enfermeiro é um facilitador nesse processo $^{(7) \text {. }}$

$\mathrm{O}$ enfermeiro, ao estar inserido em ambientes escolares, por meio do desenvolvimento de ações educativas voltadas para a construção da saúde, fortalece a relação entre a saúde e a educação. Também, contribui no enfrentamento de situações que possam ameaçar as crianças ${ }^{(6)}$.

Diante da importância do enfermeiro para o fortalecimento de ações de educação em saúde que possam minimizar danos à saúde das crianças e de evitar desfechos desfavoráveis por meio do ensino de noções de primeiros socorros, esse estudo tem como objetivo relatar o processo de ensino aprendizagem de primeiros socorros na escola por meio da utilização do Arco de Maguerez.

\section{MÉTODO}

Trata-se de um relato de experiência de uma ação de educação em saúde sobre o processo de ensino aprendizagem de primeiros socorros na escola, que utilizou para o seu desenvolvimento como base metodológica problematizadora o Método do Arco de Charlez Maguerez ${ }^{(10)}$. Esse método possibilita a participação ativa dos estudantes, por meio de suas reflexões e discussão em busca das fragilidades e resolução dos problemas vivenciados em seus cotidianos. Assim, foram implementadas as cinco etapas que compreendem: a observação da realidade, os pontos-chave, a teorização, hipóteses de solução e aplicação à realidade-prática ${ }^{(11)}$

$\mathrm{O}$ relato foi desenvolvido em uma escola municipal de ensino básico, localizada em uma cidade do Rio Grande do Sul, Brasil. E, a experiência foi desenvolvida por uma estudante de enfermagem do último ano de formação, um docente enfermeiro e um enfermeiro auxiliar da pesquisa no segundo semestre de 2018.

Participaram do estudo 138 crianças com idades entre 6 e 12 anos completos. Os 
critérios de inclusão foram: aceitar participar do estudo e ter o assentimento e consentimento formalizado pelos pais e/ou responsáveis. Os critérios de exclusão compreenderam as crianças que não quiseram participaram das oficinas educativas.

Os temas ensinados nas oficinas discorreram sobre parada cardiorrespiratória e engasgo. Os estudantes foram divididos em

\section{RESULTADOS}

$\mathrm{O}$ processo de ensino aprendizagem desenvolvido com as crianças foi descrito de acordo com as cinco etapas propostas pelo Arco de Maguerez e estão representados no dez grupos, que continham entre 12 e 15 crianças.

O estudo cumpriu com todas as normas regulamentadoras que exigem as pesquisas que envolvem seres humanos conforme a Resolução 466/2012. O projeto foi submetido e aprovado pelo Comitê de Ética em Pesquisa, sob o parecer $\mathrm{n}^{\mathrm{o}} 2.722 .813$ em 19 de junho de 2018.

Quadro 1- Sistematização do processo de ensino aprendizagem. Nesse, constam as etapas, o objetivo de cada etapa e os desfechos de cada ação desenvolvida.

Quadro 1- Sistematização do processo de ensino aprendizagem

\begin{tabular}{|c|c|c|}
\hline Etapa & Objetivo & Desfechos \\
\hline $\begin{array}{l}\text { 1.Observação } \\
\text { da realidade }\end{array}$ & $\begin{array}{l}\text { Oportunizar } r \text { às } \\
\text { crianças } \\
\text { aproximação com o } \\
\text { tema "primeiros } \\
\text { socorros", permitindo } \\
\text { a formulação do } \\
\text { problema. }\end{array}$ & $\begin{array}{l}\text {-Identificar o conhecimento que as crianças } \\
\text { possuem sobre primeiros socorros. } \\
\text {-Identificar na criança as dificuldades em } \\
\text { realizar os primeiros socorros; } \\
\text {-Realizar o levantamento das dúvidas das } \\
\text { crianças acerca da aplicação dos primeiros } \\
\text { socorros. }\end{array}$ \\
\hline $\begin{array}{l}\text { 2.Pontos- } \\
\text { chave }\end{array}$ & $\begin{array}{l}\text { Promover a reflexão e } \\
\text { discussão } \\
\text { sobre as questões } \\
\text { levantadas } \\
\text { crianças na etapa de } \\
\text { observação } \\
\text { realidade, } \\
\text { estabelecendo }\end{array}$ & $\begin{array}{l}\text {-Reflexão coletiva dos alunos acerca das } \\
\text { questões levantadas. } \\
\text {-Elaboração dos pontos essenciais a serem } \\
\text { estudados sobre o tema, para compreendê-lo } \\
\text { mais profundamente. }\end{array}$ \\
\hline
\end{tabular}




\begin{tabular}{|c|c|c|}
\hline & pontos-chave. & \\
\hline 3.Teorização & $\begin{array}{l}\text { Promover a busca de } \\
\text { informações sobre a } \\
\text { reanimação } \\
\text { cardiorpulmonar e } \\
\text { manobra } \\
\text { desengasgo. }\end{array}$ & $\begin{array}{l}\text {-Construção coletiva do conhecimento. } \\
\text {-Compartilhamento do poder entre os } \\
\text { indivíduos envolvidos no processo de } \\
\text { ensino-aprendizagem. }\end{array}$ \\
\hline $\begin{array}{l}\text { 4.Hipóteses } \\
\text { de solução }\end{array}$ & $\begin{array}{l}\text { Elaborar soluções para } \\
\text { as questões tratadas, } \\
\text { subsidiadas pelas } \\
\text { informações } \\
\text { acessadas/levantadas } \\
\text { pelas crianças e } \\
\text { fornecidas pela } \\
\text { enfermeira. }\end{array}$ & $\begin{array}{l}\text {-Produção dos projetos propostos pelas } \\
\text { crianças, destacados pela inovação e } \\
\text { criatividade (inovação ensino-aprendizagem } \\
\text { com bonecos e prática com colegas). } \\
\text {-Motivação acentuada em aprender } \\
\text { (motivada pela possibilidade de salvar o } \\
\text { colega e/ou familiar). } \\
\text {-Apresentação dos bonecos de reanimação. } \\
\text {-Apresentação do folder ilustrativo e em } \\
\text { linguagem acessível para a faixa etária. } \\
\text {-As crianças apresentaram comportamento } \\
\text { de protagonismo no seu aprendizado acerca } \\
\text { dos temas elencados por eles mesmos. } \\
\text {-Proposta de aplicação à realidade, } \\
\text { elaboradas coletivamente. }\end{array}$ \\
\hline $\begin{array}{l}\text { 5.Aplicação à } \\
\text { realidade }\end{array}$ & $\begin{array}{l}\text { Aplicar à realidade o } \\
\text { produto da atividade } \\
\text { desenvolvida. }\end{array}$ & $\begin{array}{l}\text {-Realização das oficinas de reanimação e } \\
\text { manobra de desengasgo nos bonecos. } \\
\text {-Associação da prática com o folder } \\
\text { educativo. } \\
\text {-Socialização do conhecimento produzido. } \\
\text {-Satisfação das crianças expressas em } \\
\text { desenvolver as atividades e difundir os } \\
\text { resultados para os colegas e/ou familiares. }\end{array}$ \\
\hline
\end{tabular}

Fonte: Os autores 
A primeira etapa, observação da realidade, foi realizada por meio de um convite aos estudantes para responderem a um questionário, que continha questões como: "Você sabe o que é uma parada cardiorrespiratória? ", "Você consegue explicar o que é?", Você sabe onde devemos sentir o coração de uma pessoa batendo? ", "Você sabe o que é o engasgo?".

Essa primeira etapa teve como objetivo oportunizar às crianças uma aproximação com o tema "primeiros socorros", a qual permitiu a formulação do problema. O problema identificado foi a necessidade de ampliar o conhecimento das crianças sobre a atuação em casos que necessitam de reanimação cardiopulmonar e de desengasgo, pois identificou-se que elas possuíam um breve conhecimento teórico sobre os temas, mas que não tinham habilidades para executar as manobras caso presenciassem essas situações no seu cotidiano.

A segunda etapa, denominada de pontos-chave, teve como objetivo promover a reflexão e a discussão coletiva sobre as questões levantadas pelas crianças na etapa de observação da realidade. Assim, realizou-se uma roda de conversa com as crianças a fim de proporcionar uma reflexão coletiva do conhecimento acerca das questões levantadas e a elaboração dos pontos essenciais a serem estudados sobre o tema, para compreendê-los profundamente. Essa etapa apontou a necessidade da elaboração de materiais teóricos que facilitassem a compreensão da temática bem como, a execução na prática das manobras de reanimação cardiorrespiratória e de desengasgo.

$\mathrm{Na}$ teorização, que é a terceira etapa, buscou-se promover a busca de informações sobre a reanimação cardiorrespiratória e o desengasgo. Assim, houve o compartilhamento de conhecimento entre os envolvidos no processo de ensino aprendizagem, por meio da apresentação de um folder educativo, ilustrativo e em linguagem acessível para facilitar a compreensão das informações de acordo com a faixa etária dos estudantes.

O folder educativo estava constituído por uma história em quadrinhos com imagens de personagens de um desenho animado e, continha as informações do passo-a-passo das manobras na sequência das seguintes questões: "O que fazer em situações em que o coração parar de bater?" e "O que fazer em caso de alguém estar engasgado?". As imagens com personagens de desenho animado fizeram com que o material despertasse a atenção das crianças. E, a linguagem acessível facilitou a compreensão das informações. 
A utilização da história em quadrinhos, como uma tecnologia educativa, para ensinar primeiros socorros é uma estratégia adequada e relevante para auxiliar no processo de ensino. A educação em saúde quando garante a compreensão das informações auxilia na redução do déficit de conhecimento da população ${ }^{(12)}$. Essa afirmação, corrobora com a importância do folder elaborado pelas pesquisadoras que foi utilizado para ensino das crianças.

O compartilhamento de saberes sobre o folder foi realizado em uma roda de conversa. A roda de conversa permitiu expor as ideias, tirar dúvidas e identificar estratégias para o fortalecimento do ensino aprendizagem. Dentre essas estratégias identificou-se a necessidade de oficinas práticas que ensinassem as manobras de reanimação cardiorrespiratória e de desengasgo.

$\mathrm{Na}$ etapa hipóteses de solução, buscou-se elaborar soluções para as dúvidas levantadas pelas crianças a partir do folder educativo. Tendo em vista a importância de manter as crianças motivadas em aprender apresentou-se os bonecos de reanimação para as oficinas práticas. A inovação no ensino aprendizagem para as crianças foi marcada pela possibilidade de simular as manobras nos bonecos, o que foi expresso na postura de protagonismo delas. Assim, os temas elaborados coletivamente puderam ser aplicados à realidade.

As propostas formativas das áreas da saúde e da educação nas escolas para o ensino de primeiros socorros possui alguns desafios, por isso é relevante difundir a teoria e a prática nesse espaço ${ }^{(6)}$. A escola é um espaço que favorece a troca de saberes e o aprendizado, o que suscita na consolidação do conhecimento e na formação das pessoas para transformar o contexto social onde estão inseridas ${ }^{(7)}$.

Para a aplicação à realidade, inicialmente fez-se um círculo no pátio da escola onde todas as crianças pudessem observar as manobras em bonecos e entender a explicação. As manobras foram executadas pelo enfermeiro auxiliar da pesquisa, pelo docente enfermeiro e pela estudante de enfermagem do último ano de formação, Após, dividiu-se a turma em pequenos grupos para a realização das simulações práticas.

As crianças executaram as manobras de reanimação cardiorrespiratória em bonecos de treinamento. Inicialmente elas avaliavam a cena, chamavam a pessoa, checavam o pulso carotídeo, avaliavam a respiração, pediam que alguém ligasse para o serviço de emergência e iniciavam as compressões torácicas no local indicado para as compressões. O ensino da manobra seguiu as diretrizes da American Heart Association ${ }^{(13-14)}$. 
Quanto ao ensino da manobra de desengasgo, a enfermeira pesquisadora era a vítima engasgada e o auxiliar de pesquisa demonstrava os passos para o desengasgo. A pesquisadora colocava as mãos no pescoço, demonstrando sinal de asfixia. O auxiliar de pesquisa ensinava a sequência da conduta correta para o desenvolvimento da manobra. Assim, primeiro avisava a pessoa que iria ajudá-la, posicionava-se nas costas da pessoa engasgada e realizava a manobra de Heimlich. Após assistirem as demonstrações, as crianças formavam duplas para simular a situação entre elas.

As simulações foram importantes para avaliar o processo de ensino aprendizagem, momento que também foram sanadas as dúvidas que surgiam. As dúvidas mais comuns estavam relacionadas ao posicionamento das mãos e a quantidade de compressões que poderiam fazer durante a manobra de reanimação cardiopulmonar. Após todas as crianças realizarem as manobras, houve a socialização do conhecimento construído e a associação da prática com a teoria que constava no folder educativo.

Nas situações de PCR, a avaliação e o atendimento precoce devem ser eficazes, para que contribuam positivamente na sobrevida da vítima. A sobrevivência a este evento com o mínimo possível de sequelas, depende de uma série de ações essenciais, que correspondem à "cadeia de sobrevivência" indicada pela AHA. Portanto, possuir conhecimentos e habilidades para prestar auxílio de forma adequada e sistemática a um cidadão, pode representar a diferença entre a vida e a morte ${ }^{(5,13)}$.

As oficinas de simulações práticas mostraram-se como uma estratégia positiva no ensino aprendizagem, pois foi possível observar a motivação das crianças em aprender e a executar as manobras. Também, por expressarem satisfação diante da possibilidade de disseminar o conhecimento para os familiares. É indispensável que o acesso ao conhecimento de primeiros socorros seja difundido para toda a sociedade. Isso, contribui diretamente na redução do número de vítimas que vão a óbitos por desconhecimento e despreparo ${ }^{(7)}$.

Há a necessidade de implementação de disciplinas em escolas públicas que abordem diversos conteúdos de primeiros socorros nos currículos para que os estudantes possam aperfeiçoar o conhecimento nessa área. Desse modo, é imprescindível que os modelos curriculares das escolas brasileiras sejam revisados $^{(7)}$. Alguns estudos apontam para a necessidade e a efetividade de ações educativas que sejam desenvolvidas de modo contínuo nas escolas ${ }^{(15)}$. 
No que tange ao uso da metodologia ativa de aprendizagem, essa estimula 0 protagonismo, a criatividade e a autonomia das pessoas, pois engloba habilidades de comunicação, cognição e interação social. Diante disso, apresenta um potencial para a formação de sujeitos que sejam autônomos, participativos e envolvidos com mudanças sociais $^{(16)}$. O Arco de Maguerez, enquanto metodologia ativa, permite atuar sobre os problemas sociais da realidade ${ }^{(17)}$.

Diante do exposto, o uso da metodologia da problematização por meio do Arco de Maguerez se mostrou importante à medida que organizou o processo de ensino aprendizagem e permitiu a constante reflexão, compartilhamento de ideias e a formação dos sujeitos envolvidos. Sendo assim, sugere-se o uso dessa metodologia para subsidiar no ensino de escolares bem como, a inserção dos enfermeiros nos espaços formativos.

\section{CONCLUSÃO}

O método do Arco de Maguerez mostrou-se essencial para a operacionalização do processo de ensino aprendizado, pois facilitou o desenvolvimento de habilidades pelas crianças e proporcionou $\mathrm{O}$ compartilhamento de saberes entre os envolvidos. Diante da possibilidade que esse método oferece de partir da observação da realidade e somente após várias etapas acontecer a aplicação da ação, desencadeou com uma transformação da realidade social nas escolas.

Com a avaliação, ao final do processo, foi possível identificar que houve uma ampliação significativa no conhecimento das crianças. Após as oficinas de simulações práticas de manejo em situações de PCR e engasgo, as crianças obtiveram resultados positivos no que tange ao aprendizado, desse modo há um impacto na prática já que ocorre a transformação social. Assim, conclui-se que a implementação de oficinas para crianças na escola contribui positivamente para a troca de experiências, conscientização, construção de novos conhecimentos, diálogo e formação de seres críticos e comprometidos com a sociedade, desde a infância.

O enfermeiro, ao realizar ações de educação em saúde, desperta nas crianças uma postura ativa e desenvolve a autonomia à medida em que essas demonstram interesse e desenvolvem habilidades no manejo das situações que exigem primeiros socorros.

O presente estudo apresenta como limitação o fato de as pesquisadoras conseguirem abordar somente os temas de PCR e desengasgo devido ao tempo necessário e a complexidade do ensino nas simulações práticas. Portanto, aponta para a necessidade do engajamento dos enfermeiros nesses espaços para a ampliação dessas ações. 


\section{REFERÊNCIAS}

1. Organização Não-Governamental Criança Segura Brasil. Conheça os dados sobre acidentes: hospitalizações segundo o DATASUS do Ministério da Saúde [Internet]. São Paulo: ONG Criança Segura. 2018. Disponível em: https://criancasegura.org.br/noticia/ran king-dos-acidentes-que-mais-matame-ferem-criancas-no-brasil-2018/

2. Cunha MWN, Santos MS, Albuquerque DDTM, Farre AGMC, Santana ITS. Conhecimentos de funcionários de creches sobre primeiros socorros com crianças antes e após treinamento ativo. Cienc Cuid Saude. 2021;20:e54591. doi: https://doi.org/10.4025/cienccuidsaude . $\mathrm{v} 20 \mathrm{i} 0.54591$

3. Costa SNG, Silva JMM, Freitas BHBM, Reis AFC. Acidentes Infantis: conhecimento e percepção de educadoras de creches. Rev enferm UFPE online. 2017;11(10):3845-52. doi: $\quad$ http://10.5205/reuol.1283430982-1-SM.1110201719.4.

4. Oliveira VC, Castro MMFS, Rouberte ESC, Silva SMA, Camargo CL, Grimaldi MRM. Enfermagem e o brincar: prevenção de acidentes com pré-escolares. Braz. J. of Develop. 2020; 6(12):103351-103362. doi: https://doi.org/10.34117/bjdv6n12-729

5. Monteiro MJFSP, Pereira MCARS, Carvalho RMBC, Carril ESB, Carril MFB, Rodrigues VMCP. Capacitação de trabalhadores em suporte básico de vida. Rev. Cuid. 2018;9(2):2117-26. http://dois.org/10.15649/cuidarte.v9i2. $\underline{505}$.
6. Lima PA, Oliveira TMN, Moreira ACMG, Moreira RC Martins EAP, Costa AB. Primeiros socorros como objeto de educação em saúde para profissionais de escolas municipais. Rev.

Enferm. UFSM. 2021; 11(e10): 1-16. doi:

https://doi.org/10.5902/217976924329 $\underline{2}$

7. Santana MMR, Toledo LV, Moreira TR, Alves KR, Ribeiro L, Sá Diaz FBB. Intervenção educativa em primeiros socorros para escolares da educação básica. Rev. Enferm. UFSM. 2020;10(e70): 1-17. doi:

https://doi.org/10.5902/217976923650 7

8. Brasil. Lei $\mathrm{n}^{\circ} 13.722$, de 04 de outubro de 2018.Torna obrigatória a capacitação em noções básicas de primeiros socorros de professores e funcionários de estabelecimentos de ensino públicos e privados de educação básica e de estabelecimentos de recreação infantil. Brasília, DF, 2018. Disponível em:http://www.planalto.gov.br/ccivil_ 03/_ato2015-

2018/2018/lei/L13722.htm\#: :text=L $\mathrm{EI} \% 20 \mathrm{~N} \% \mathrm{C} 2 \% \mathrm{BA} \% 2013.722 \% 2 \mathrm{C} \%$ 20DE\%204,de\%20estabelecimentos\% $20 \mathrm{de} \% 20$ recrea $\% \mathrm{C} 3 \% \mathrm{~A} 7 \% \mathrm{C} 3 \% \mathrm{~A} 3 \mathrm{o}$ $\% 20$ infantil.

9. Ministério da Saúde (BR). Portaria ${ }^{\circ}$ 2.436, de 21 de setembro de 2017. Aprova a Política Nacional de Atenção Básica, estabelecendo a revisão de diretrizes para a organização da Atenção Básica, no âmbito do Sistema Único de Saúde (SUS). [Internet]. Brasília, DF. 21 Set. 
10. Berbel NAN. A problematização e a aprendizagem baseada em problemas: diferentes termos ou diferentes caminhos? Interface: Comunicação, Saúde, Educação. 1998;2(2):139-154. Available from: https://www.scielo.br/j/icse/a/BBqnR McdxXyvNSY3YfztH9J/?format=pdf \&lang $=\mathrm{pt}$

11. Bordenave JD, Pereira, AM. Estratégias de ensino aprendizagem. $25^{\mathrm{a}}$ ed. Petrópolis (RJ): Vozes; 2004. p.15-21.

12. Silva ASR, Ferreira SC. Construção e validação de tecnologia em saúde educacional para primeiros socorros. HU Revista. 2021;47:1-8. doi: $\quad$ https://doi.org/10.34019/19828047.2021.v47.32594

13. American Heart Association - AHA. Atualização das diretrizes da American Heart Association 2015 para RCP e ACE. 2015. Disponível em:

https://eccguidelines.heart.org/wpcontent/uploads/2015/10/2015-AHAGuidelines-Highlights-Portuguese.pdf. Acesso em: 28 out. 2018.

14. American Heart Association - AHA. Atualização das diretrizes da
American Heart Association 2015 para RCP e ACE. 2020. Disponível em: https://cpr.heart.org/-/media/cprfiles/cpr-guidelines-

files/highlights/hghlghts_2020eccguid elines_portuguese.pdf

15. Silva DP da, Nunes JBB, Moreira RTF, Costa LC. Primeiros socorros: Objeto de educação em saúde para professores. Rev enferm UFPE on line.2018;12(5):1444-53. doi: https://doi.org/10.5205/1981-8963v12i5a234592p1444-1453-2018.

16. Silva NA, Senna MAA, Teixeira MCB, Lucietto DA, Andrade IM. O uso de metodologia ativa no campo das Ciências Sociais em Saúde: relato de experiência de produção audiovisual por estudantes. Interface Comunicação, Saúde, Educação. 2020; 24(e190231). doi: https://doi.org/10.1590/Interface.1902 $\underline{31}$

17. Nascimento, B.M. Folder educativo sobre doação de leite materno durante a pandemia da covid-19. Rev Enferm Atual In Derme. 2021;95(34):e021052. doi: https://doi.org/10.31011/reaid-2021v.95-n.34-art.1051.

Submissão: 2021-06-30

Aprovado: 2021-07-12 